\section{Preserving diversity}

SIR - It would be mistaken, as RiveraNúñez and Obón-de-Castro point out (Nature 360, 291; 1992), to equate biodiversity solely with genetic diversity (measured in terms of genes, alleles, DNA), or to equate biodiversity conservation with the task of collecting and storing germplasm or DNA sequences. It is now established, as they point out, that 'real' biodiversity is the consequence of diverse interactions between individuals within biological populations, their environments and anthropic factors.

But Rivera-Núñez and Obón-deCastro continue by criticizing the established, ex situ biodiversity conservation paradigm or, as they see it, the "armchair, molecular-biased approach". They favour wildlife preservation by monitoring of endangered species and the establishment of in situ reserves and they say that local landrace material cannot be stored without an understanding of the conscious and unconscious processes that led to their appearance and distribution. They go so far as to assert that conservation of cultivated plants and domesticated animals is dependent on the survival of the cultures in which they originated. This reasoning is ill-informed, fallacious and extremely dangerous.

The consequence of Rivera-Núnez and Obón-de-Castro's sophistry is that a false, antagonistic dichotomy is established between the two predominant approaches to biodiversity conservation, ex situ and in situ techniques. When either genetic or species erosion predominates and resources for conservation are so limited, how can fellow conservationists be so foolhardy as to promulgate an unnecessary, divisive argument that will undoubtedly detract from the crucial fact that it is our duty to conserve biodiversity in whatever ways are appropriate? Surely ex situ and in situ activities should be seen as and are in fact complementary techniques that are used by biologists to conserve native biodiversity?

It is a demonstrable fact that landraces can be conserved ex situ without knowledge of the culture that produced or distributed them. It is obviously desirable to obtain as high a quality of background information relating to the conserved material as possible, especially if the material is to be utilized as well as conserved, but it is not essential.

Rivera-Núñez and Obón-de-Castro point out that ethnobiological and cultural diversity is in serious danger of loss because of the encroachment of unadapted Western culture. This problem, and the associated genetic erosion, can- not be underestimated. Ethnobiologists, anthropologists, sociologists and politicians can all work together to help aboriginal survival, combat the erosion of cultural diversity and aid conservation in the whole biosphere. This task is vast; conservationists will have a prominent part to play, but it is likely to be a much longer term goal. This goal, however, should not be formulated at the expense of shorter-term biological conservation goals, which aim to conserve croprelated germplasm ex situ for the benefit of all humanity. If we do not conserve germplasm now and wait for multidisciplinary agreement on how to conserve the entire biosphere, there may be little germplasm left to freeze and conserve At this time, surely a broad, holistic approach involving ex situ and in situ techniques is called for, and is most appropriate, if we are to preserve biodiversity for future generations.

\section{Brian Ford-Lloyd}

\section{Nigel Maxted}

School of Biological Sciences, University of Birmingham.

Edgbaston, Birmingham B15 2TT, UK

SIR - People continue to be surprised that there is no complete basic inventory of the variety of life on Earth. Some specialists champion the description of large numbers of new species on the grounds that this would facilitate the conservation of biodiversity through the recognition and comment on greater numbers of species ${ }^{1-3}$. But the description of new species needs to be viewed within cost or political constraints. And there are reasons why the potential costs of describing new species have been grossly underestimated.

For the foreseeable future, description of all the world's species will remain impossible. So much can be demonstrated empirically by dividing the estimated numbers of species to be described by the numbers described per unit time: the result is a very large figure. The number of undescribed living insect species may be in the region of 9 million ${ }^{4}$, of which about 7,250 species are described each year, for example. But such calculations do not account for the fact that a proportion of the descriptions of 'new' species are subsequently recognized to pertain to previously described species. The proportion of past descriptions thus far synonymized commonly attains levels of 20 per cent or more among groups of insects. Because this problem is compounded through time, there are obvious serious financial implications ${ }^{5}$.

Plainly, although a complete global species inventory may be unrealistic, the description of a sizeable proportion of those species is not. In the face of the extra effort needed to cope with the problems of synonymy, descriptive work will need to be carefully targeted. Already work in support of applied and theoretical studies in fields such as agriculture and medicine consume much of the available taxonomic resources.

We are concerned only with the resources left over from these projects plus any expansion that may result from recent reviews of the state of taxonomy. Taxonomic work for biodiversity conservation will continue to be severely constrained by the availability of appropriate expertise, and, without clear guidelines as to the conservationists' priorities, it will not be possible to provide an appropriate taxonomic framework.

Taxonomy, like other disciplines, is driven by the interests of individual scientists. Descriptive effort is thus widely dispersed, in every sense. By contrast, three approaches might target descriptive effort in support of the conservation of biodiversity: to concentrate efforts and resources upon a few selected groups, on a few selected areas or on a few selected systems. More communication between taxonomists and conservationists is necessary to meet these ends.

\section{Kevin J. Gaston}

\section{Lawrence A. Mound}

Department of Entomology,

Natural History Museum,

Cromwell Road, London SW7 5BD, UK

1. Soulé, M. E. Ann. Missouri Bot. Gard. 77, 4-12 (1990)

2. Wilson, E. O. Issues Sci. Technol. 2, 20-29 (1985)

3. Wilson, E. O. in Biodiversity (ed. Wilson, E. O.) 3-18 (National Academy Press, Washington, DC, 1988).

4. Hammond, P. M. in Global Biodiversity, Status of the Earth's Living Resources (ed. Groombridge, B.) 17-39 (Chapman and Hall, London, 1992).

5. Gaston, K. J. \& Mound, L. A. Proc. R. Soc. (in the press).

\section{Due credit}

SIR - Perhaps the present Vatican deserves more credit for rehabilitating Galileo than you give it (Nature 360, 2; 1992). From my own observation, I believe the dogma of the Church is much influenced by who the Pope and his advisers happen to be at any given time. In seeking to understand the natural explanation for the evolution of life, from repeatable and repeated experiments, the present Pope is ahead of many in the scientific community. With rehabilitation of Galileo and with openness to modern views of Genesis, the Vatican under Pope John Paul II appears to signal a more informed relationship between science and religion.

\section{SIdney W. Fox}

Mineralization Center,

University of South Alabama,

Mobile, Alabama 36688, USA 